\title{
VFR TRAVELERS: HOW LONG ARE THEY STAYING?
}

\author{
ELISA BACKER \\ School of Business, University of Ballarat, Ballarat, Victoria, Australia
}

\begin{abstract}
The Visiting Friends and Relatives (VFR) segment of travelers is a substantial segment of tourism in many destinations around the world. However, relative to its size, research has been lacking, commencing only around 20 years ago, and gaining momentum only this century. Research into VFR traveler profiles and characteristics has been limited, and some of what has been found conflicts with other findings. One such conflict relates to travelers' length of stay. While some research indicates that VFR travel is associated with long length of stay, other research indicates that it is associated with short-break tourism. The purpose of this research was to examine the length of stay for VFR travelers compared with non-VFR travelers at three contrasting destinations in Australia. Although the average length of stay varied among destinations, there was no significant difference between VFR and non-VFR travelers at each destination. That is, in this study VFR travel was not found to be associated with either short or long stay at the three destinations considered. However, length of stay was longer the more popular the destination was with tourists. As such, it is concluded that VFR travelers stay at more attractive destinations longer than at less attractive destinations, but not at any significantly different level to non-VFRs.
\end{abstract}

Key words: Visiting friends and relatives (VFR) travel; Length of stay

\section{Introduction}

Visiting Friends and Relatives (VFR) travel can be described as travel involving visits to friends and/or relatives. Due to the size (by volume) of VFR travel in many regions, it is often recognized as a major tourism segment. However, despite this, it is "one of the most neglected areas of study" (Page \& Connell, 2009, p. 94). In comparison to its size, there has been little research into VFR travelers, their motivations, behaviors, and characteristics, and the factors that influence their choices. This has led to their lack of recognition in destination marketing organization (DMO) marketing plans and an assumption that they contribute little to local economies and tourism industries.

Numerous research gaps are evident in the extant literature. This research aims to examine one of these areas, focusing on the length of stay of VFR travelers relative to non-VFR travelers in three contrasting tourist regions. Length of stay is a critical component of tourism examination, leading to obvious benefits to local economies due to additional funds accrued to tourism industries. This aspect has been particularly confusing in the 
literature, with mixed findings apparent. Therefore, it is still unknown whether VFR travelers stay for longer or shorter time than other travelers. Through considering the relative difference between VFRs and non-VFRs at three different destinations in one country, Australia, it is intended that more can be revealed about this large and important form of travel.

\section{Literature Review}

Considering the size of VFR travel, relatively little research has been undertaken in the field. Academic research in the field is somewhat new, with the first major study being only two decades ago (Jackson, 1990). Jackson's article struck a chord with a number of researchers, creating curiosity concerning VFR through the mid-1990s. However, VFR travel failed to maintain the momentum in interest, with relatively little literature resulting until more recently.

VFR travel has been highlighted through previous research as being historically ignored and underestimated (Braunlich \& Nadkarni, 1995; Hay, 1996, 2008; Jackson, 1990, 2003; King, 1996; McKercher, 1994, 1995; Morrison, Hseih, \& O'Leary, 1995; Seaton, 1994; Seaton \& Palmer, 1997; Seaton \& Tagg, 1995; Yaman, 1996). The reason VFR travel has failed to attract the level of research it may deserve is an interesting point. While VFR travel is one of the largest and most significant forms of travel, and is also recognized as being a sizable form of travel worldwide, "VFR travel remains well-known but not known well" (Backer, 2009, p. 2). It is often overlooked in terms of marketing campaigns, and many researchers consider that the area has been forgotten and largely ignored ( $\mathrm{Hu} \&$ Morrison, 2002; Pennington-Gray, 2003, Young, Corsun, \& Baloglu, 2007).

There have been various reasons put forward as to why VFR travel tends to be neglected despite its size. Jackson $(1990,2003)$ suggests it is largely a classification problem. Despite tourism marketing organizations failing to champion it or undertake dedicated marketing strategies to capture these travelers, Lee, Morrison, Lheto, Webb, and Reid (2005) feel that these organizations cannot afford to marginalize VFR travel because it is "buoyant" (p. 35). Paci (1994) blames the "poorly documented" (p. 36) data for the neglect in this field, which Hay (2008) also recognizes, stating that VFR started life as a "residual classification" that did not belong in the main categories of tourism (p. 1). As such, it has always been seen as an ancillary form of tourism. Seaton and Palmer (1997) considered three perception problems causing the neglect of VFR travel. These three perceptions are: it has a low economic impact, it cannot be influenced by tourism planners, and it cannot be influenced by marketing. Backer (2010a) took extended this idea, providing eight reasons to explain this neglect, each of which will be discussed in this article. They are:

1. Definitional difficulties

2. Discrepancy with existing data

3. Difficulties with measurement

4. Lack of lobbying

5. Perceived minor economic impact

6. Poor representation in tourism textbooks

7. Perception that VFR travelers are difficult to influence

8. Perception that VFR is not "sexy"

The first point is particularly interesting. With few attempts to provide a comprehensive definition for VFR travel, it suggests a lack of thinking that underpins the field. In a number of cases (e.g., Lee et al., 2005; Hu \& Morrison, 2002), no definition is provided but the authors state that dat were collected by purpose of visit, which reveals an assumed definition for VFR travel in this manner. While it is reasonable to assume that readers will have an overall understanding of what VFR stands for, it does overlook the data collection problem that VFR is commonly categorized by purpose of visit, but it can also be categorized by accommodation type (Seaton \& Palmer, 1997). Different percentages will be obtained depending on which classification is used, and neither should be considered a comprehensive definition (Backer, in press).

However, VFR travel has also been classified in terms of accommodation. King (1994) stated that VFR travel categorizes visitors by the type of accommodation they used. Boyne, Carswell, and Hall (2002) proposed that "a VFR tourism trip is 
a trip to stay temporarily with a friend or relative away from the guest's normal place of residence, that is, in another settlement or, for travel within a continuous settlement, over $15 \mathrm{~km}$ one-way from the guests' home" (p. 246). They admitted that this definition "largely avoids rather than confronts some of the key conceptual issues" (pp. 246-247). Similarly, Kotler, Bowen, and Makens (2006) state that "VFR, as the name suggests, are people that stay in the homes of friends and relatives" (p. 748). These suggestions reinforce the implied notion that VFR travelers do not stay in commercial accommodation. In fact, according to Navarro and Turco (1994), the perception that VFR travelers make little use of commercial accommodation and do not tend to frequent restaurants, cafés, ${ }_{r}$ ubs, and clubs is why VFR travel has not been clearly defined.

A definition was put forward by Backer (2007) that "VFR travel is a form of travel involving a visit whereby either (or both) the purpose of the trip or the type of accommodation involves visiting friends and/or relatives" (p. 369). This has since been used as the basis for a definitional model (Fig. 1) to visually highlight that there are in fact three distinct VFR types, and by measuring VFR by purpose of visit or accommodation type, only two of the three groups will ever be measured.

\begin{tabular}{|l|l|l|}
\cline { 2 - 4 } \multicolumn{1}{c|}{} & $\begin{array}{l}\text { Accommodation: } \\
\text { Friends \& family }\end{array}$ & $\begin{array}{l}\text { Accommodation: } \\
\text { Commercial }\end{array}$ \\
\hline $\begin{array}{l}\text { Purpose } \\
\text { of Visit: } \\
\text { VFR }\end{array}$ & & \\
\hline $\begin{array}{l}\text { Purpose } \\
\text { of Visit: } \\
\text { Non-VFR }\end{array}$ & PVFRs & \\
\hline
\end{tabular}

Figure 1. VFR definitional model. PVFRs, pure VFRs (people who are staying with friends or relatives and also state a VFR purpose of visit); EVFRs, exploiting VFRs (people who are staying with friends or relatives but did not travel for the purpose of visiting them); CVFRs, commercial VFRs (people who traveled to a destination for the purposes of visiting a friend or relative but stay in commercial accommodation). Source: Backer (2010b, p. 45).
VFR travelers who stay with friends and relatives and also state a primary purpose of visit as being VFR are considered in the above model to be "pure" VFRs (PVFRs). This is represented in the top left-hand quadrant in the matrix. Below that are EVFRs, who stay with their friends and relatives but this is not their purpose of visit. They are, in a sense, exploiting their friends and relatives. In the top right quadrant, CVFRs who have come to the destination specifically or primarily to visit their friends and relatives but elect to stay in commercial accommodation are represented.

With definitional considerations only now appearing in the literature, it is not surprising that this has been considered one of the causes for neglect in the area of VFR travel. This also helps to improve an understanding of why the discrepancy with existing data exists, which is the second reason for neglect of the VFR segment. The size of VFR in terms of purpose of visit is not the same as the size of VFR by accommodation. By referring to VFR by purpose of visit data, which can be substantially different to the proportion of VFRs by accommodation data, an underestimation of VFR size results.

VFR travel can be a difficult segment to measure, which leads to the third reason for what might be termed "VFR neglect." VFR travelers might be staying in commercial accommodation or with friends and relatives, and it can be resource intensive to gather adequate data to measure this. The "emphasis on gathering data from commercial accommodation houses" (King, 1996, p. 87) necessarily underreports VFR travel as well. This contributes to VFR being underestimated and neglected.

Lack of lobbying is another cause for neglect. Hay $(1996,2008)$ highlighted this as one of the central problems of VFR travel: it lacks a lobbying group. Accommodation providers often take up the majority of seats on DMO boards and represent a substantial membership composition. These board members are likely to perceive that VFR travelers are not part of their customer base, so to date there has been no place on a board of directors of a DMO for a representative to promote VFR travel. The strategic direction of the marketing efforts will be geared towards other areas by those in a position to champion other causes. King 
(1996) takes this further by stating that there is actually lobbying against research into VFR travel. He claims that in some countries there is lobbying, primarily by the accommodation sector, against using public funds to undertake research in this area.

With relatively little research into VFR travel, and some lobbying against it, little research has been undertaken to explore its economic impact. In fact, VFR travel tends to hold secondary status within tourism (Lehto, Morrison, \& O'Leary, 2001). VFR travelers are considered to be of inconsequential value to a local economy; spend little and do little in terms of mainstream tourism activities (Backer, 2010b). However, the problem is one of perception rather than actuality, with research by McKercher (1994) and King (1994) highlighting the value of VFR travel to local economies.

Furthermore, VFR travel is said to be less susceptible than other forms of tourism to seasonality issues (Aseidu, 2008; Bull, 1995; Denman, 1988; Hay, 1996; McKercher, 1994; Seaton \& Palmer, 1996; Seaton \& Tagg, 1995; Weaver \& Lawton, 2010), and "is most likely to fall outside the conventional tourism season" (Aseidu, 2008, p. 617). Therefore, the reduced seasonality aspect of VFR travel compounds its stabilizing effect on local economies.

A further reason for the neglect of VFR travel as a segment relates to tourism textbooks. Despite its size, VFR travel is given, at best, a cursory mention in tourism textbooks (Backer, 2010a). Except perhaps a column in a table, or a few paragraphs at best, VFR barely makes it to the index of many current tourism educational books and does not even rate a place in the index of others. Tourism textbooks serving as critical reading and learning tools for future tourism managers, and serve as the basis for a teaching template in tertiary education, yet VFR is regularly omitted from the teaching syllabus, resulting in the continuation of VFR travel being neglected (Backer, 2009).

Another reason that contributes to VFR travel's neglected status is the issue of how to influence VFR travelers. It has been considered to be a form of tourism that happens "naturally" and that cannot be influenced (Morrison et al., 2000, p. 110). However, VFR hosts are considered to hold a highly influential role concerning the activities that are undertaken by VFR travelers (Jackson, 2003; Meis, Joyal, \& Trites, 1995; McKercher, 1995; New Zealand Tourism Board, 1986; Yuan, Fridgen, Hseih, \& O'Leary, 1995). Tourists tend to rely on the advice provided by friends and relatives in selecting a destination ( $\mathrm{Hu} \&$ Morrison, 2002; Young et al., 2007). Therefore, local residents are likely to have a key role in VFR travel, not only in influencing the actual VFR trip, but in determining VFR behavior regarding local activities and attractions once they arrive.

An eighth and final reason as to why VFR travel tends to be neglected is that it is not regarded as a "sexy" area of marketing (Backer, 2010a). International marketing is often regarded as more high level and prestigious, and is speci fied in the charters of many national tourism organizations (Backer, 2010a). It can also be said that "marketing to 'Aunt Betty' is not as glamorous" (Backer, 2010a, p. 340).

With relatively little regard for VFR, and with the many assumptions regarding the behaviors of VFR travelers, it is not surprising so little is known about the characteristics and behaviors of this segment. Length of stay is one of those behaviors about which little is known. While research has been undertaken to consider this aspect, there is no consensus regarding length of stay or its influence.

Many studies have discussed the length of stay of VFR travelers and the issue of relativity; that is, whether VFR travelers stay longer, shorter, c the same time as other travelers has been discussed by a smaller number of studies. These studies revealed different findings. Some researchers claimed that VFR travelers are associated with a long length of stay (Bull, 1995; Lee et al., 2005; MacEachern, 2007; Polak, 1993; Yuan et al., 1995); others reported a short length of stay (Boyne, 2001; Fache, 1994; Hay, 1996; McKercher, 1994, 1995).

Seaton (1994) found that international VFR travelers to the UK had a longer length of stay. However, he also recognized that tourism operators that deal with short-break travel will typically find that more than half of their market comprises VFR travelers (Seaton, 1994).

While VFR travel has been associated with both short-break and long-stay travel, further dif- 
ferences in length of stay may be found where VFR is disaggregated into VF and VR trips. Based on an analysis of UK data, Hay (1996) found that VR trips (average of 3.7 nights) were longer than VF trips (average 2.1 nights). However, once compared with the holiday segment (average of 5.5 nights) both VF and VR trips were still comparatively short (Hay, 1996).

The length of stay for VFR travelers is interesting from a commercial accommodation perspective. According to Lehto et al. (2001), VFR travelers staying in commercial accommodation have a longer length of stay than other tourists. This issue is important in terms of the economic impact that VFR travel has on a local economy. Similarly, Braunlich and Nadkarni (1995) found that VFR avelers staying in commercial accommodation exhibited significantly longer lengths of stay than the pleasure market.

However, the impact of destination on length of stay has not been considered. The aim of this research is to therefore consider whether VFR travelers have a long or short length of stay, relative to non-VFR travelers. In order to address this research question, both VFR and non-VFR travelers were surveyed and three different destinations along the eastern seaboard of Australia selected, in order to understand the impact that destination type may have on how long VFR travelers like to stay.

\section{Method}

Quantitative research was considered the most appropriate for this study. As a structured data collection process was required, questionnaires were selected based on face-to-face surveying. This was considered the most appropriate means of gathering responses from both VFRs and non-VFRs. The idea of mailing out surveys was dismissed as this would involve inconsistent methods of capturing VFR travelers and non-VFR travelers. That is, VFR travelers would be contacted through their hosts' address while non-VFR travelers would have to be contacted through accommodation houses. Telephone surveys were also dismissed as a possibility, as they would not be an appropriate method to capture visitors without accessing databases.
Face-to-face street surveys were considered most suitable because a variety of busy locations can be easily identified and selected. A key advantage of this method is that all completed responses can be collected within a relatively short period of time and any doubts respondents may have about any question can be clarified on the spot (Sekaran, 2000). The researcher can also "motivate the respondents to give frank answers" (Sekaran, 2000, p. 234). Street surveys were considered the best approach in order to have a consistent method for surveying all groups (VFR travelers and non-VFR travelers). They were also considered the best approach for reducing bias of the respondents since a broader range of respondents could be included.

\section{Sampling Zone}

Three destinations along the eastern seaboard of Australia were selected as sampling zones (Fig. 2). The Sunshine Coast, located around $100 \mathrm{~km}$ north of the State of Queensland's capital, Brisbane, was selected as one area to undertake this research. The Sunshine Coast region has a population over 260,000 people (Australian Bureau of Statistics [ABS], 2008), and is the 10th largest population area in Australia (Sunshine Coast Australia, 2009). It is one of Australia's most popular holiday destinations (Weaver \& Lawton, 2010) and ranks in the top 10 destination regions in Australia for inbound visitors (Weaver \& Lawton, 2010) and in the top five regions in Australia ranked by expenditure (Tourism Research Australia [TRA], 2009).

The second destination, Townsville, is located north of the Sunshine Coast. It has a population over 180,000 (ABS, 2008) and is the largest city in north Queensland. As it is adjacent to the center of the Great Barrier Reef, it is popular with tourists, and also boasts large sporting events, the nearby Magnetic Island, and popular walking tracks (James Cook University [JCU], 2010).

The third destination, Ballarat, is located in the state of Victoria, around an hour's drive from the state capital, Melbourne. Ballarat has a population of around 90,000 (ABS, 2008). It has a number of tourist attractions, such as the Observatory and Ballarat Wildlife Park, but is best known for its open-air museum Sovereign Hill. Sovereign Hill 


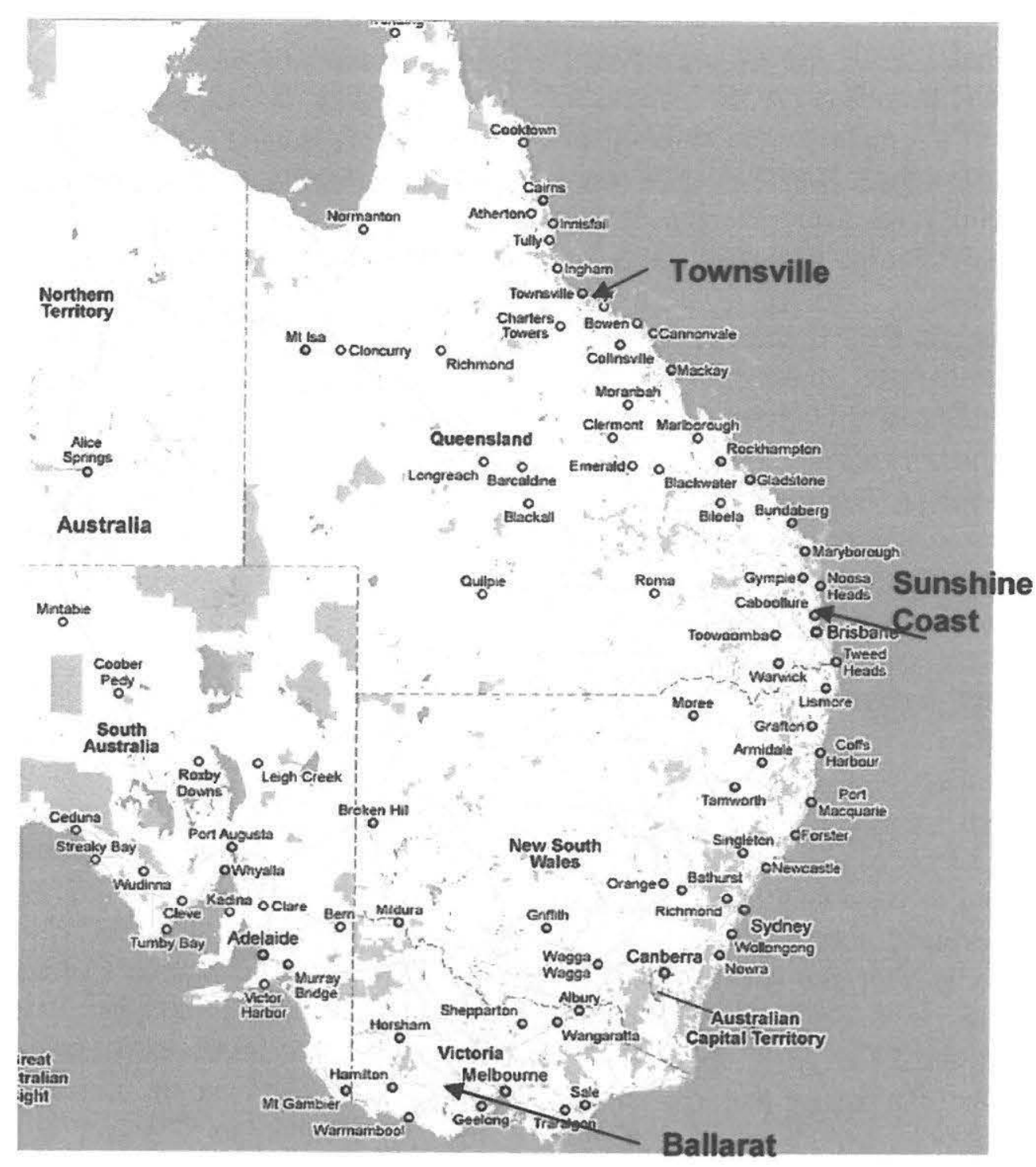

Figure 2. Map of Australia with three sampling zones. Source: adapted from Google Maps 2010 (http://maps.google.com.au/?ie=UTF8\&ll=-26.863281,147.612305\&spn=29. $664917,39.506836 \& \mathrm{z}=5 \& \mathrm{pw}=2$ )

is a popular major attraction in Victoria, but due to Ballarat's proximity to Melbourne, often suffers from being used primarily as a day-tripper destination. Unlike Townsville and the Sunshine Coast, Ballarat does not have a commercial airport.

The substantial differences in these destinations in terms of climate, popularity, infrastructure, and population provided sufficient contrast for examining the issue of length of stay for VFRs based on different destinations. While smaller, more remote destinations exist, it was considered vital from a resource perspective to encounter reasonable numbers of overnight visitors in order to collect data.

In the Sunshine Coast, 738 visitor surveys were collected. Data were disaggregated into VFR and
non-VFR based on the VFR definitional model (Fig. 1), capturing a total of 229 VFRs and 509 non-VFRs. In Townsville, 132 surveys were collected, with 64 VFR surveys and 68 non-VFR surveys. In Ballarat, the total number of surveys collected was 254, comprising 98 VFRs and 156 non-VFRs.

\section{Results}

Visitors to each of the three destinations were asked "How many nights are you staying?" Analysis of these results enabled the assessment of the comparative length of stay for VFR and non-VFR travelers staying at each location. As the largest 
Table 1

Relationship Between Length of Stay for VFR and Non-VFR Travelers to the Sunshine Coast (Raw Data)

\begin{tabular}{lcrccc}
\hline Sunshine Coast & $n$ & Mean & SD & Median & Mode \\
\hline VFR & 227 & $10.3^{*}$ & 21 & 5 & 7 \\
Non-VFR & 509 & $7.8^{*}$ & 13 & 6 & 7 \\
\hline
\end{tabular}

*Significant at the $95 \%$ confidence level.

sample size came from the Sunshine Coast, indepth statistical analysis was undertaken on those results to determine a plan for testing at the other destinations.

Raw data indicated that VFR travelers stayed .tore nights than non-VFR travelers at the Sunshine Coast (Table 1). However, as outliers skewed the data and violated the assumption of normality, data were converted to logarithmic functions. A $t$-test of the logarithmic data to test for significant differences between the length of stay for VFR and non-VFR travelers indicated there was no difference at the $95 \%$ confidence level (Table 2). As such, length of stay (number of nights) was unaffected by visitor types, with both VFR and non-VFR travelers staying for similar durations of time.

At Townsville, VFR travelers stayed an average of 5.4 nights, compared with non-VFR travelers' 4.6 nights (Table 3). Again, due to the skewed ature of the data, they were converted to logarithmic functions and the $t$-test was undertaken on the $\log$ data. The test revealed no significant difference in length of stay (on the log data) at the $95 \%$ confidence level.

In Ballarat, VFR travelers stayed an average of 3.52 nights, compared with non-VFR travelers'

Table 2

Relationship Between Length of Stay for VFR and Non-VFR Travelers to the Sunshine Coast (Log Means)

\begin{tabular}{lcccc}
\hline Sunshine Coast & $n$ & Log Mean & SD & SEM \\
\hline VFR & 227 & 0.74 & 0.439 & 0.029 \\
Non-VFR & 509 & 0.73 & 0.336 & 0.015 \\
\hline
\end{tabular}

Levene statistic $=18.46(p<0.05), t(349)=0.294(p>0.05)$.
Table 3

Relationship Between Length of Stay for VFR and Non-VFR Travelers to Townsville

\begin{tabular}{llc}
\hline Townsville & $n$ & Mean \\
\hline VFR & 64 & $5.4(\mathrm{~ns})$ \\
Non-VFR & 68 & $4.6(\mathrm{~ns})$ \\
\hline
\end{tabular}

ns: not significant.

3.23 nights (Table 4). After converting the raw data to logarithmic functions to normalize the skew of the data, a $t$-test was undertaken on the log data. The test revealed no significant difference in length of stay (on the log data) at the $95 \%$ confidence level.

As a larger sample size in the Sunshine Coast enabled further disaggregation of data, testing between the three VFR types based on the VFR definitional model (Fig. 1) was undertaken. The purpose for this was to see if any differences in length of stay between the VFR types could be established to explain the differences exhibited in the literature.

Table 5 presents the mean results for the raw data as well as log means. Analysis of these results enabled the assessment of the length of stay for the three VFR types that were staying at the Sunshine Coast. There was no statistically significant difference for the length of stay for the different VFR typologies. Statistical tests were undertaken on the log means, as outliers in the data violated the rule of normality and as such the data were converted to logarithmic functions. A test of the homogeneity of variances revealed that differences in the length of stay across the three groups were not significant at the $95 \%$ confidence level. The ANOVA result was not significant, and individual post hoc tests using Tukey HSD at the $95 \%$ confi-

Table 4

Relationship Between Length of Stay for VFR and Non-VFR Travelers to Ballarat

\begin{tabular}{lrc}
\hline Ballarat & $n$ & Mean \\
\hline VFR & 98 & $3.52(\mathrm{~ns})$ \\
Non-VFR & 156 & $3.23(\mathrm{~ns})$ \\
\hline
\end{tabular}

ns: not significant. 
Table 5

Relationship Between Length of Stay and VFR Typologies (Sunshine Coast)

\begin{tabular}{|c|c|c|c|c|c|c|c|}
\hline & \multirow[b]{2}{*}{$n$} & \multirow[b]{2}{*}{ Mean (Nights) } & \multirow[b]{2}{*}{ Log Mean (Nights) } & \multirow[b]{2}{*}{$\mathrm{SD}$} & \multicolumn{3}{|c|}{ Tukey HSD (Mean Difference) } \\
\hline & & & & & PVFR & CVFR & EVFR \\
\hline PVFR & 124 & 9.7 & 0.74 & 0.42 & N/A & & \\
\hline CVFR & 60 & 14.3 & 0.81 & 0.50 & 0.070 & N/A & \\
\hline EVFR & 45 & 6.7 & 0.65 & 0.39 & -0.085 & -0.155 & N/A \\
\hline
\end{tabular}

Levene statistic $=0.626(p>0.05), f(0.615)=1.607(p>0.05)$.

dence level revealed no statistically significant difference between any of the sets in terms of length of stay.

\section{Discussion and Conclusion}

This research has revealed that VFR and nonVFR travelers exhibited a similar length of stay in the Sunshine Coast, Townsville, and Ballarat. The study revealed no statistically significant difference between the two groups of VFRs and nonVFRs at the three destinations. This is in contrast to the findings established through the literature search, which had revealed different results with regards to VFR length of stay, with some studies indicating that VFRs have a longer length of stay to that of non-VFRs whereas others stated that VFRs are inclined to have shorter lengths of stay.

This aspect of mixed findings for length of stay was noted by Aseidu (2008), who stated that the longer length of stay reported by Lee et al. (2005) could be associated with "the fact that a large number of VFR travellers stay in non-paying residences with friends and relatives, contrasting with non-VFR travellers who stay mainly in commercial accommodations" (p. 612).

A larger sample size in the Sunshine Coast enabled further disaggregated to examine the issue of the difference in length of stay among the three VFR types. CVFR travelers, who stay in commercial accommodation, were found to stay longer than the other VFR travelers (PVFRs and EVFRs). However, once these data were converted to logarithmic functions, the difference was not significant.

The data collected for this study included some VFR travelers who had very long lengths of stay. This necessarily skewed the data and violated the rule of normality. It is unknown whether other studies also experienced outliers in their data and, if so, how these were addressed. VFR travel may be more typically associated with outliers, with extremely long lengths of stay, compared wit other forms of travel. Therefore, further research to explore this in other destinations would be useful to "help illuminate the actual relevance of this variable in decision making among VFR" travelers (Asiedu, 2008, p. 612).

This research has contributed to the literature in several ways. Firstly, it has contributed to the body of knowledge in VFR travel, which, relative to the size of the segment on a global perspective, is small and limited. Secondly, this research has assisted to improve knowledge on the mixed findings regarding length of stay for VFR travelers. Based on three different destinations, there was no significant difference between VFR and non-VFR length of stay once data were converted to loga rithmic functions to normalize the skew and enable $t$-tests to be conducted. Thirdly, and perhaps more interestingly, this research highlights the impact destination can have on VFR length of stay. The most popular destination of the three, the Sunshine Coast, enjoyed the longest trip duration for both VFR and non-VFR travelers. The destination with the least appeal for tourism, Ballarat, revealed the shortest length of stay for both VFRs and non-VFRs. As such, VFR travelers stay at more attractive destinations longer than at less attractive destinations, but not at any significantly different level to non-VFRs. If, indeed, VFR travel is purely about visiting friends and relatives, then the attractiveness of the destination should have no influence. However, VFRs seem to want to stay longer when the destination is attractive. There- 
fore, it seems that VFRs can be influenced not only by their hosts, but by where the hosts reside. Further investigation into the host-destination relationship would add greatly to knowledge in this important and sizable tourism segment.

\section{References}

Asiedu, A. (2008). Participants' characteristics and economic benefits of visiting friends and relatives (VFR) tourism-an international survey of the literature with implications for Ghana. International Journal of Tourism Research, 10(6), 609-621.

Australian Bureau of Statistics. (2008). 3235.0-Population by age and sex, regions of Australia, 2007. Canberra, Australia: Author.

Backer, E. (2007). VFR travel-an examination of the expenditures of VFR travellers and their hosts. Current Issues in Tourism, 10(4), 366-377.

Backer, E. (2009). The VFR trilogy. Paper presented at The 19th Council for Australian University Tourism and Hospitality Education (CAUTHE) Conference, February 10-13, Fremantle, Western Australia, Australia.

Backer, E. (2010a). Opportunities for commercial accommodation in VFR travel. International Journal of Tourism Research, 12(4), 334-354.

Backer, E. (2010b). VFR travel: An assessment of VFR versus non-VFR travelers. Germany: VDM Verlag Dr. Müller.

Backer, E. (in press). VFR Travel: It IS underestimated. Tourism Management.

Boyne, S. (2001). Hosts, friends and relatives in rural Scotland: VFR tourism market relationships explored. In L. Roberts \& D. Hall (Eds.), Rural tourism and recreation: Principles to practice (pp. 41-43). Wallingford, UK: CABI.

syne, S., Carswell, F., \& Hall, D. (2002). Reconceptualising VFR tourism: Friends, relatives and migration in a domestic context. In C. M. Hall \& A. M. Williams (Eds.), Tourism and migration: New relationships between production and consumption (pp. 241-256). Dordrecht, Netherlands: Kluwer Academic.

Braunlich, C., \& Nadkarni, N. (1995). The importance of the VFR market to the hotel industry. Journal of Tourism Studies, 6(1), 38-47.

Bull, A. (1995). The economics of travel and tourism (2nd ed.). Melbourne, Australia: Longman.

Denman, R. (1988). A response to the VFR market. BTA/ ETB consultancy report. Retrieved from http://www.lin coln.ac.nz/PageFiles/7235/Backer.pdf

Fache, W. (1994). Short break holidays. In A. V. Seaton (Ed.), Tourism: The state of the art (pp. 459-467). Chichester, UK: Wiley.

Hay, B. (1996). An insight into the European experience: A case study on domestic VFR tourism within the UK. Paper presented at the Victoria University of Technology Conference, October, Melbourne, Australia.
Hay, B. (2008). An exploration of the differences in the volume and value of visiting friends and visiting relatives' tourism in the UK. Paper presented at The 18th Council for Australian University Tourism and Hospitality Education (CAUTHE) Conference, February 1114, Gold Coast, Queensland, Australia.

Hu, B., \& Morrison, A. (2002). Tripography: Can destination use patterns enhance understanding of the VFR market? Journal of Vacation Marketing, 8(3) 201-220.

Jackson, R. (1990). VFR tourism: Is it underestimated? The Journal of Tourism Studies, 1(2), 10-17.

Jackson, R. (2003). VFR tourism: Is it underestimated? (original 1990 article reprinted). The Journal of Tourism Studies, 14(1), 17-24.

James Cook University. (2010). Townsville. Retrieved August, 12, 2010 from http://www.jcu.edu.au/international/ campuses/JCUPRD_017203.html

King, B. (1994). What is ethnic tourism? An Australian perspective. Tourism Management, 15(3), 173-176.

King, B. (1996). VFR-a future research agenda. Paper presented at the VFR Tourism: Issues and implications Conference, Melbourne, Australia.

Kotler, P., Bowen, J., \& Makens, J. (2006). Marketing for hospitality and tourism (4th ed.). Upper Saddle River, NJ: Pearson Education.

Lee, G., Morrison, A., Lheto, X., Webb, J., \& Reid, J. (2005). VFR: Is it really marginal? A financial consideration of French overseas travellers. Journal of Vacation Marketing, 11(4), 340-356.

Lehto, X., Morrison, A., \& O'Leary, J. (2001). Does the visiting friends and relatives' typology make a difference? A study of the international VFR market to the United States. Journal of Tourism Research, 40, 201212.

MacEachern, M. (2007). Characteristics of the visiting friends and relatives markets in Prince Edward Island: A longitudinal approach. Paper presented at the Travel and Tourism Research Association (TTRA) Annual Conference, Nice, France. Retrieved from http://www. trc.upei.ca/files/TTRA_2007_PEI_VFR_Market_Paper. pdf

McKercher, B. (1994). Report on a study of host involvement in VFR travel to Albury Wodonga. Albury, Australia: Tourism Albury Wodonga.

McKercher, B. (1995). An examination of host involvement in VFR travel. Paper presented at the National Tourism and Hospitality Conference, February, Melbourne, Australia.

Meis, S., Joyal, S., \& Trites, A. (1995). The U.S. repeat and VFR visitor to Canada: Come again eh! The Journal of Tourism Studies, 6(1), 27-37.

Morrison, A., Hseih, S., \& O'Leary. J. (1995). Segmenting the visiting friends and relatives market by holiday activity participation. The Journal of Tourism Studies, 6(1), 48-63.

Navarro, R., \& Turco, D. (1994). Segmentation of the visiting friends and relatives travel market. Visions in Leisure and Business, 13(1), 4-16. 
New Zealand Tourism Board. (1986). Australian VFR and repeat visitors to New Zealand: An initial study. Wellington, New Zealand: Author.

Paci, E. (1994). The major international VFR markets. EIU Travel \& Tourism Analyst, 6, 36-50.

Page, S., \& Connell, J. (2009). Tourism: A modern synthesis (3rd ed.). Andover, UK: South Western Cengage Learning.

Pennington-Gray, L. (2003). Understanding the domestic VFR drive market in Florida. Journal of Vacation Marketing, 9(4), 354-367.

Polak, L. (1993). How significant is VFR to Australian tourism? Armidale, Australia: University of New England'Northern Rivers.

Seaton, A. V. (1994). Are relatives friends? Reassessing the VFR category in segmenting tourism markets. In A. V. Seaton (Ed.), Tourism: The state of the art (pp. 316-321). Chichester, UK: Wiley.

Seaton, A. V. (1996). Making (even more) sense of the VFR category in tourism analysis. Paper presented at the Victoria University of Technology Conference, October, Melbourne, Australia.

Seaton, A. V., \& Palmer, C. (1996). The structure of domestic VFR tourism in the UK 1989-1993, and what it tells us about the VFR category. Paper presented at the Victoria University of Technology Conference, October, Melbourne, Australia.

Seaton, A., \& Palmer, C. (1997). Understanding VFR tour- ism behaviour: The first five years of the United Kingdom tourism survey. Tourism Management, 18(6), 345355.

Seaton, A. V., \& Tagg, S. (1995). Disaggregating friends and relatives in VFR tourism research: The Northern Ireland evidence 1991-1993. The Journal of Tourism Studies, 6(1), 6-18.

Sekaran, U. (2000). Research methods for business-a skill-building approach. Chichester, UK: John Wiley \& Sons.

Sunshine Coast Australia. (2009). Sunshine Coast general overview. Retrieved July 6, 2010, from http://www.sun shinecoast-australia.com/sunshine-coast-general-over view.html

Tourism Research Australia. (2009). Travel by Australians-December 2008 quarterly results of the National Visitors Survey. Canberra, Australia: Author.

Weaver, D., \& Lawton, L. (2010). Tourism management (4th ed.). Milton, UK: Wiley.

Yaman, H. (1996). VFR tourism: Issues and implication. Paper presented at the Victoria University of Technology Conference, October, Melbourne, Australia.

Young, C., Corsun, D., \& Baloglu, S. (2007). A taxonomy of hosts: Visiting friends and relatives. Annals of Tourism Research, 34(2), 497-516.

Yuan, T., Frigden, J., Hseih, S., \& O'Leary, J. (1995). Visiting friends and relatives: The Dutch case. The Journal of Tourism Studies, 6(1), 19-26. 